Plant Tissue Cult. \& Biotech. 18(1): 57-63, 2008 (June)

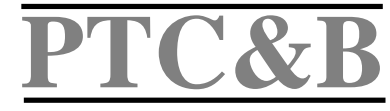

\title{
Improved Salt Tolerance and Morphological Variation in Indica Rice (Oryza sativa L.) Transformed with a Catalase Gene from $E$. coli
}

\author{
Shamsul H. Prodhan*1, A. Hossain ${ }^{2}$, Kenji Nagamiya ${ }^{1}$, \\ Atsushi Komamine ${ }^{3}$, Hiroko Morishima ${ }^{1}$ \\ Department of Agricultural Science, Tokyo University of Agriculture, Tokyo, Japan \\ Key words: Rice, Oxidative stress, Enhanced salt tolerance, Transformation, \\ Morphological variation
}

\begin{abstract}
In an attempt to improve the salt tolerance of rice, we introduced katE, a catalase gene of Escherichia coli, into the indica rice cultivar Kasalath. Transformation was carried out using Agrobacterium tumefaciens strain EHA101 harboring a binary

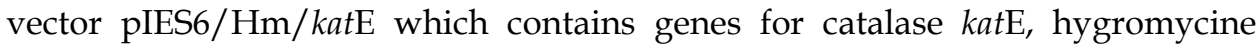
resistance gene HPT and kanamycin resistance gene NPTII in the T-DNA region. With the inclusion of acetosyringone, higher amount of transgenic cells and regenerated plants were obtained. Transformation was confirmed by PCR with $k a t \mathrm{E}$ and HPT primer. Transgenic plants at a very young stage (three - four days) were able to grow up to 15 days in $100 \mathrm{mM} \mathrm{NaCl}$ solution and seven days in 250 $\mathrm{mM} \mathrm{NaCl}$ solution whereas control plants died within five days in $100 \mathrm{mM}$ and seven days in $50 \mathrm{mM} \mathrm{NaCl}$. Plants stressed for four weeks could survive for a long time and were able to flower. Different morphological characters varied in transgenic compared to control plants. Introduction of katE gene significantly improved the salt tolerance of the transgenic indica lines which could mature and set seed under stress.
\end{abstract}

\section{Introduction}

Salinity is one of the major abiotic stresses that cause severe loss of rice production. Salt tolerance is a complex trait because it is regulated by various mechanisms. Organisms that thrive in hyper saline environments possess different mechanisms to adjust the internal osmotic status under stress. One mechanism is the ability to accumulate low molecular organic compatible solutes such as sugars, some amino acids and quaternary ammonium compounds, which are believed to be essential for adaptability of plant cells to high salinity (Bohnert et al. 1995). 
${ }^{*}$ Corresponding author. E-mail: <shamsulhp@yahoo.com>11Department of Biotechnology, Shahjalal University of Science and Technology, Sylhet-3114, Bangladesh. ${ }^{2}$ Bangladesh Sugarcane Research Institute, Ishurdi, Pabna, Bangladesh. ${ }^{3}$ The Research Institute of Evolutionary Biology. 2-4-28, Kamiyoga, Setagaya-ku,Tokyo, 158-0098, Japan.

Another mechanism is the the ability of some plants to sequester. Na cations away from sodium sensitive sites, by proteins such as the $\mathrm{Na}^{+} / \mathrm{H}^{+}$ antiporter and $\mathrm{Na}^{+}$ATPase (Serrano 1996). Salt accumulation also induces oxidative stress. Enzymes that can remove the reactive oxygen species (ROS) produced by the salt stress play an important role in tolerance. Thus quenching of $\mathrm{H}_{2} \mathrm{O}_{2}$ was an important factor for salt tolerance as observed in cyanobacteria (Kaku et al. 2000). Nagamiya et al. in 2007 were able to produce salt tolerant japonica rice (at $100 \mathrm{mM}$ salt concentration) by over expressing the catalase gene katE. Catalase is one of the major and stable antioxidant enzymes which break down hydrogen peroxide producing $\mathrm{H}_{2} \mathrm{O}$ and $\mathrm{O}_{2}$, helping plants to survive. Normally catalase is expressed in microbodies, mitochondria and chloroplasts but not in the cytosol. This research was conducted to transform the recalcitrant indica rice Kasalath, with the E. coli derived katE gene (Kaku et al. 2000). Salt tolerance of the transgenic plants at different growth stages and their morphological variation has been reported and compared with control plants.

\section{Materials and Methods}

Plant material and bacterial strain: Oryza sativa L. indica cultivar Kasalath was used in this research and mature seeds were used as explant. The vector was constructed by Nagamiya et al. 2007 and the vector pIES6/katE/Hm was transformed into Agrobacterium tumefaciens strain EHA101 by electroporation. Transformation was carried out by using the Agrobacterium tumefaciens strain EHA101 harboring the vector $\mathrm{pIES6/Hm/katE} \mathrm{(Hood} \mathrm{et} \mathrm{al.} \mathrm{1986).} \mathrm{This} \mathrm{is} \mathrm{a} \mathrm{binary}$ vector that contains genes for catalase $k a t \mathrm{E}$, hygromycin resistance gene HPT and kanamycin resistance gene NPTII in the T-DNA region.

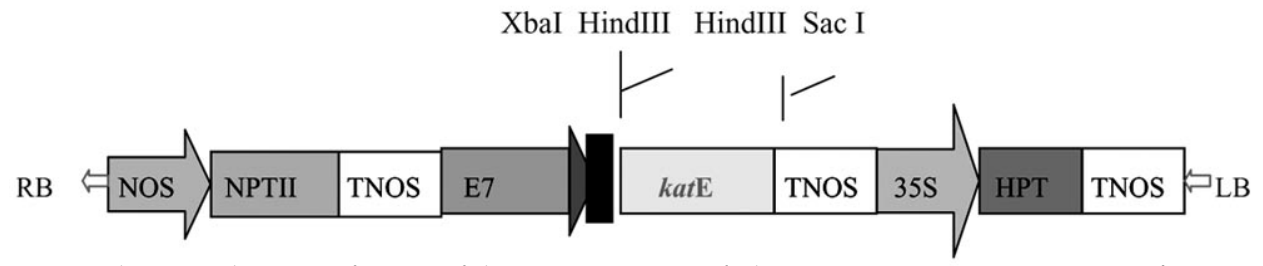

Fig. 1. Schematic diagram of a part of the T-DNA region of plant expressing vector pIES6katE/Hm. $\mathrm{RB}$, right border; NOS, nopaline synthatase promoter; NPTII, neomycin phosphotransferase II; TNOS, terminator of nopaline synthatase; 35S, Cauliflower mosaic virus promoter; E7, seven enhancer region (- 290 to - 90) from CaMV promoter; katE, catalase katE gene; HPT, gene for hygromycin phosphstransferase; LB, left border. 
Transformation and culture condition: Transformation of rice was conducted using the established methods of Hiei et al. (1994) and Toki (1997). Callus was induced from mature rice seeds on $\mathrm{N} 6$ medium supplemented with $2 \mathrm{mg} / 1$ 2,4-D. After two weeks induced calli were infected with Agrobacterium tumefaciens EHA101 carrying pIES6katE/Hm. After three days of co-culture with the inclusion of acetosyringone, callus was sterilized with $500 \mathrm{mg} / 1$ carbenicillin and grown in $\mathrm{N} 6$ selection medium containing $50 \mathrm{mg} / \mathrm{l}$ hygromycin and $500 \mathrm{mg} / 1$ carbenicillin for two weeks. Resistant calli were transferred to hormone-free MS for regeneration. Regenerated plantlets were acclimated in pots $(15 \mathrm{~cm}$ diameter) with soil and submerged with water in a growth incubator at $30^{\circ} \mathrm{C}$ (light phase) and $25^{\circ} \mathrm{C}$ (dark phase) with 12 hours light at $71 \mathrm{~m}$ mole $\mathrm{m}^{-2} \mathrm{~s}^{-1}$ photon flux density and $62 \%$ relative humidity. Progenies were obtained from those transgenic plants by selfing.

PCR analysis: Genomic DNA was extracted from young leaf tissues of $\mathrm{T}_{0}$ transgenic and control plants. PCR was performed in a reaction mixture containing about $25 \mathrm{ng}$ plant genomic DNA, $100 \mu$ mole dNTP, $0.2 \mu$ mole of each primer and $1 \mathrm{U}$ of Taq polymerase (Takara, Japan). PCR analysis was carried out under standard condition with 30 second denaturation, 40 second annealing, 50 second extension at 94,50 and $72^{\circ} \mathrm{C}$, respectively for 30 cycles. The sequence of the PCR primers were as follows: 1165U (CCACCAAGT TCTATACCGAAGAGG) and 1165 L (GTGATATTCAGCTGGTCGTCAGTC).

Morphological variation and salt stress study: Mature salt water treated transgenic plants were checked for various morphological characters comparing with the non-transgenic plants such as plant height, first leaf length, root length, number of panicles per hill, panicle length, number of spikelets per panicle, filled grain percentage etc. together with control plants. Relative plant height was also measured.

Transgenic and non-transgenic plants at two different stages were used to evaluate salt tolerance. In first stage after acclimatization of $\mathrm{T}_{0}$ transgenic and wild plants were grown for three days in pot soil and then in 0, 50, 100, 150, 200, 250 and $300 \mathrm{mM}$ (half of the sea water level) of sodium chloride solutions were added. In case of second growth stage acclimatized $T_{0}$ transgenic and control plants were grown for four weeks in pot soil and then they were treated with the above mentioned solutions. For each concentration, at least two plants were used. Water was added untill the mark on vessels every two days to maintain the same concentration of $\mathrm{NaCl}$ in the vessels. $\mathrm{T}_{1}$ plants were also used for salt water test.

\section{Results and Discussions}


Transformation and regeneration with PCR analysis: We transformed the recalcitrant Indica rice cultivar Kasalath with the katE gene derived from E. coli. The gene was expressed under the control of the 35S RNA promoter of the cauliflower mosaic virus with E7 enhancer. We infected the calli with a binary

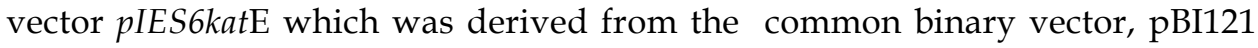
(Ohta et al. 1990). Rashid et al. (1996) used the same vector to obtain transgenic Basmati rice. In some reports, a super binary vector, in which a DNA fragment from the virulence region was more effective for transformation of rice. Hiei et al. (1994) described that recalcitrant cultivars can be more easily transformed by using this super binary vector. However, Hashizume et al. (1999) obtained high transformation frequencies by using a conventional binary vector. In this study a conventional binary vector was used to obtain transformants from recalcitrant indica rice cultivars.

Transformation and regeneration frequencies were $80.0 \pm 2.9$ and $51.4 \pm 7.9 \%$, respectively. This was obtained using the $100 \mu \mathrm{M}$ acetosyringone in comparison with $50 \mu \mathrm{M}$ concentration. We have detected the insertion of katE and HPT genes by PCR from randomly selected $T_{0}$ plants (Fig. $3 \mathrm{a}, \mathrm{b}$ ). The results showed the presence of transgene in all transformants examined and transgenic plants carrying katE gene were obtained with high efficiency. At 100 $\mu \mathrm{M}$ acetosyringone concentration, transformation and regeneration values were as high as some japonica cultivars (Hiei et al. 1994) and the indica cultivar Basmati 370 (Rashid et al. 1996). According to James et al. 1993, acetosyringone treatment has been reported to be highly effective for increased transformation. In this experiment also addition of higher concentration of acetosyringone (100 $\mu \mathrm{M})$ showed better results both transformation and regeneration.
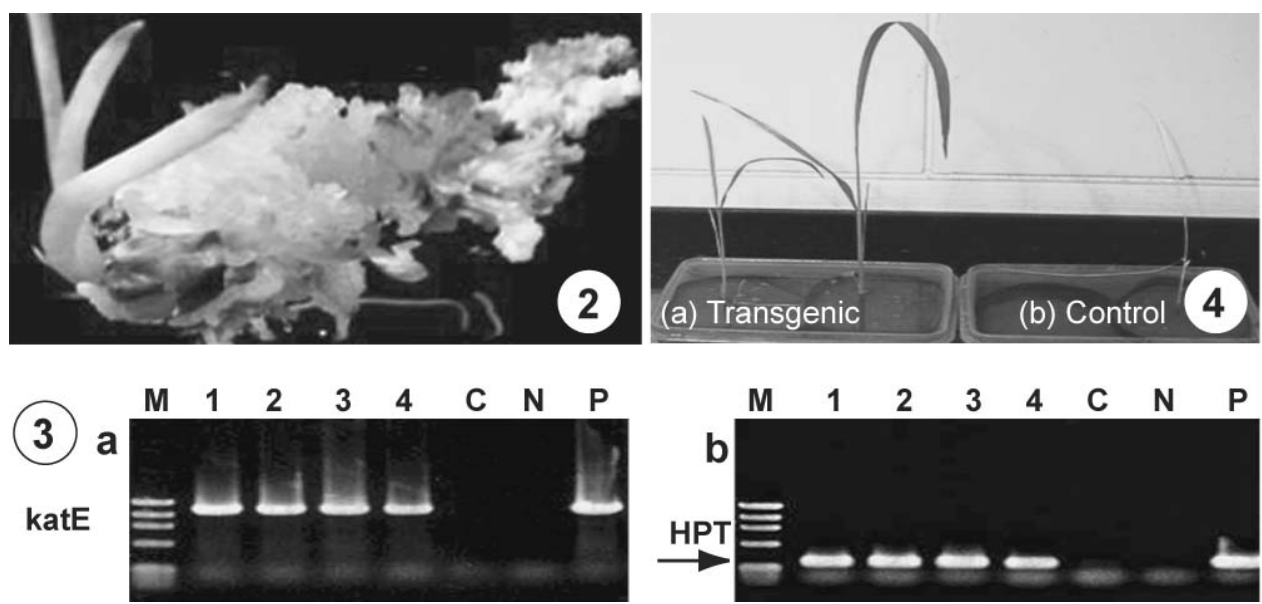

Figs. 2-4: 2. Regeneration of transgenic calli on MS regeneration medium. 3(a) PCR analysis of $\mathrm{T}_{0}$ Kasalath plants for presence of katE gene (1165 bp) and (b) HPT gene (350 bp). M, for marker $\lambda$ Hind III and Hae III; Lane 1-4, transgenic plants, C, control; N, negative control and P for 
positive control. 4(a) three-day-old $\mathrm{T}_{0}$ plants and (b) control plant in $100 \mathrm{mM} \mathrm{NaCl}$ solution five days after salt water treatment.

Phenotypic characterization and salt tolerance: Various morphological traits of transgenic plants were observed at the time of maturity in comparison with nontransformants. As shown in Table 1, transformants had shorter plant height, leaf, root and panicle length, smaller panicle and spikelet number and seed fertility compared to the non-transformants. Some transgenic lines without salt water treatment showed seed fertility from 62 to $97 \%$ and control plants showed seed fertility from 92 to $98 \%$ (data not shown).

Table 1. Phenotypic variation of transgenic and non-transgenic Kasalath plants.

\begin{tabular}{lcc}
\hline $\begin{array}{l}\text { Character } \\
\text { evaluated }\end{array}$ & $\begin{array}{c}\text { Transgenic } \\
\text { plants }\end{array}$ & $\begin{array}{c}\text { Non-transgenic } \\
\text { plants }\end{array}$ \\
\hline Plant height $(\mathrm{cm})$ & $103.0 \pm 3.5$ & $111.7 \pm 3.2$ \\
First leaf length $(\mathrm{cm})$ & $8.9 \pm 0.6$ & $11.1 \pm 1.7$ \\
Root length $(\mathrm{cm})$ & $13.8 \pm 1.3$ & $13.06 \pm 1.4$ \\
No. of panicle/hill & $3 \pm 0$ & $3 \pm 0$ \\
Panicle length $(\mathrm{cm})$ & $22.6 \pm 0.6$ & $24.1 \pm 0.9$ \\
Filled grain \% & $89.2 \pm 3.4$ & $95 \pm 5.1$ \\
Awn & Some are awned & Mostly awned \\
\hline
\end{tabular}

${ }^{*}$ Four to six plants were tested for the experiment.

We evaluated $\mathrm{T}_{0}$ transgenic and non-transgenic plants for salt tolerance. At $100 \mathrm{mM}$ sodium chloride solution, plants at young stage (three days grown on pot soil) survived until 15 days and control plants for four days (Fig. 4).

Same aged transgenic plants at $250 \mathrm{mM}$ concentration survived up to eight days whereas control plants died on the second day. Four weeks grown transgenic plants were treated with salt water where $T_{0}$ plants could form inflorescence at $100 \mathrm{mM}$ and could grow 25 days in $250 \mathrm{mM}$ sodium chloride (Table 2). On the contrary wild rice plants could not survive even in the presence of $50 \mathrm{mM}$ sodium chloride for more than seven days and no seed was formed.

Table 2. Salt water treatment of transgenic (after four weeks grown on pot soil) and wild rice plants.

\begin{tabular}{|c|c|c|c|c|c|c|c|c|c|c|}
\hline \multirow{2}{*}{$\begin{array}{l}\text { In } 100 \mathrm{mM} \\
\text { conc. }\end{array}$} & \multicolumn{10}{|c|}{ Days after treatment } \\
\hline & 3 & 6 & 9 & 10 & 13 & 15 & 18 & 20 & 25 & 35 \\
\hline Wild plants & +++ & +++ & ++ & ++ & + & - & - & - & - & \\
\hline $\mathrm{T}_{\mathrm{o}}$ & +++ & +++ & +++ & +++ & +++ & +++ & +++ & +++ & +++ & +++ \\
\hline \multirow{2}{*}{$\begin{array}{l}\text { In } 250 \mathrm{mM} \\
\text { conc. }\end{array}$} & \multicolumn{10}{|c|}{ Days after treatment } \\
\hline & 3 & 6 & 9 & 10 & 13 & 15 & 18 & 22 & 25 & 35 \\
\hline Wild plants & ++ & - & - & - & - & - & - & - & - & - \\
\hline
\end{tabular}




\begin{tabular}{lllllllllllllllll}
$\mathrm{T}_{\mathrm{o}}$ & +++ & +++ & +++ & +++ & +++ & ++ & ++ & ++ & + & - \\
\hline
\end{tabular}

$+++=$ All leaves are green at good condition, $++=$ Some portion of leaves are bleached,

$+=$ Maximum portion of leaves is bleached, $-=$ Almost dead.

At the time of salt water treatment relative plant height was measured. Transgenic plant height at $200 \mathrm{mM}$ increased and survived up to 20 days but the height of the control plants was lower and on the ninth day their growth stopped and died at the 12th day (Fig. 5).

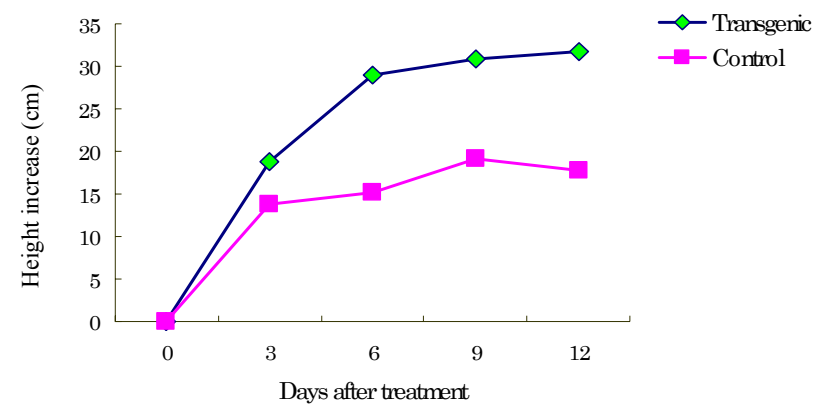

Fig. 5. Increase of height after treatment of $\mathrm{T}_{0}$ plants under $200 \mathrm{mM} \mathrm{NaCl}$ conc..

A good deal of efforts have been made to develop salt tolerant rice plants by introduction of genes encoding proteins involved in protecting plants from environmental stress such as chloroplastic glutamine synthase (GS2), betain aldehyde dehydrogenase, calcium dependant protein kinase (CDPK) etc. Transformed rice plants with GS2 gene could survive for two weeks at $150 \mathrm{mM}$ sodium chloride (Hoshida et al. 2000). A gene encoding betaine aldehyde dehydrogenase, an enzyme involved in the synthesis of glycine betaine (CODA) that could produce a compatible solute regulating internal osmotic balance was introduced into rice genome and rice plants could survive one week at $150 \mathrm{mM}$ sodium chloride (Sakamoto et al. 1998). Another gene encoding CDPK was introduced to rice plants where transformed rice plants could survive for three days at $200 \mathrm{mM}$ sodium chloride (Saijo et al. 2000). In cyanobacteria, the introduction of a catalase gene katE from E. coli was found to reduce ROS production under salt stress and to confer salt tolerance (Kaku et al. 2000). However, salt tolerant transgenic rice plants, which have been reported so far, were able to form seeds in japonica transformants at $100 \mathrm{mM} \mathrm{NaCl}$ at the maximum (Nagamiya et al. 2007). Transgenic indica rice plants with katE gene derived from $E$. coli as reported here, were able to form inflorescence in $100 \mathrm{mM}$ or lower concentration of $\mathrm{NaCl}$ at different growth stages. They could survive for one month in $150 \mathrm{mM}$ and for 20 days in 200 and $250 \mathrm{mM} \mathrm{NaCl}$. Here, we report the expression of katE gene and its salt resistance effect in $\mathrm{T}_{0}$ indica rice plants with their phenotypic variation. 


\section{Acknowledgement}

The authors are grateful to Dr. Tatsuhito Fujimura, Institute of Life and Environmental Sciences, The University of Tsukuba, Mr. Masateru Yamanaka and Mr. Masataka Asada, Department of Agriculture, Tokyo University of Agriculture, for their technical advice and valuable comments.

\section{References}

Bohnert HJ, Nelson D and Jensen RG (1995). Adaptations to environmental stress. Trends Biotechnol. 14: 89-97.

Hashizume F, Tsuchiya T, Ugaki M, Niwa Y, Tachibana N and Kowyama Y (1999). Efficient Agrobacterium-mediated transformation and the usefulness of a synthetic GFP reporter gene in leading varieties of Japonica rice. Plant Biotechnol. 16(5): 397401.

Hiei Y, Komari T and Kumashiro T (1994). Efficient Transformation of rice (Oryza sativa L.) mediated by Aagrobacterium tumefaciens and sequence analysis of the boundaries of the T-DNA. The Plant J. 6(2): 271-282.

Hood EE, Helmer GL, Freiley RT and Chilton MD (1986). The Hypervirulence of Agrobacterium tumefaciens is encoded in a region of pTiBo542 outside of T- DNA. J. Bacteriol. 168: 1291-1301.

Hoshida H, Tanaka Y, Hibino T, Hayashi Y, Tanaka A, Takabe T and Takabe T (2000). Enhanced tolerance to salt stress in transgenic rice that overexpresses chloroplast glutamine synthase, Plant Mol. Biol. 43: 103-111.

James DJ, Uratsu S, Cheng J, Negri P, Viss P and Dandekar AM (1993). Acetosyringon and osmoprotectants like betaine or praline synergistically enhance Agrobacterium mediated transformation of apple. Plant Cell Rep. 12: 559-563

Kaku N, Hibino T, Meng Y, Tanaka Y, Araki E, Takabe T and Takabe T (2000). Effects of overexpression of Escherichia coli katE and bet genes on the tolerance for salt stresss in a fresh water Ccyanobacterium synechococcus sp. PCC 7942. Plant Science 159: $281-288$.

Nagamiya K, Motohashi T, Nakao K, Prodhan SH, Hattori E, Hirose S, Ozawa K, Ohkawa Y, Takabe T, Takabe T and Komamine A (2007). Enhancement of salt tolerance in transgenic rice expressing an Escherchia coli catalase gene, katE. Plant Biotechnology Reports 1(1): 49-55.

Ohta M, Hayashi Y, Nakashima A, Hamada A, Tanaka A, Nakamura T and Hayakawa T (2002). Introduction of a Na+/ $\mathrm{H}^{+}$antiporter gene from Atriplex gmelini confers salt tolerance to rice. FEBS Letters 532: 279-282.

Rashid H, Yokoi S, Toriyama K and Hinata K (1996). Transgenic plant production mediated by Agrobacterium in Indica rice. Plant Cell Reports 15: 727-730.

Sakamoto A, Murata A and Murata N (1998). Metabolic engineering of rice leading to biosynthesis of glycinebetaine and tolerance to salt and cold, Plant Mol. Biol. 38: 1011-1019.

Saijo Y, Hata S, Kyozuka J, Shimamoto K and Izui K (2000). Over-expression of a single $\mathrm{Ca}^{+}$- dependent protein kinase confers both cold and salt/drought tolerance on rice plants, Plant J. 23 : 319-327. 
Serrano R (1996). Salt tolerance in plants and microorganisms: toxicity targets and defense responses. Int. Rev. Cytol. 165: 1-52

Toki S (1997). Rapid and efficient Aagrobacterium-mediated transformation in rice. Plant Molecular Biol. 15(1): 16-21. 